\title{
Defects in glycopeptidolipid biosynthesis confer phage 13 resistance in Mycobacterium smegmatis

\begin{abstract}
Correspondence
Apoorva Bhatt

a.bhatt@bham.ac.uk
\end{abstract} \\ Received 29 July 2009 \\ Revised 5 September 2009 \\ Accepted 7 September 2009 \author{
Gurdyal S. Besra ${ }^{1}$ and Apoorva Bhatt ${ }^{1}$
${ }^{1}$ School of Biosciences, College of Life and Environmental Sciences, University of Birmingham, Edgbaston, Birmingham B15 2TT, UK
${ }^{2}$ Howard Hughes Medical Institute, Department of Microbiology and Immunology, Albert Einstein College of Medicine, 1300 Morris Park Avenue, Bronx, NY 10461, USA \\ Jiemin Chen, ${ }^{1}$ Jordan Kriakov, ${ }^{2}$ Albel Singh, ${ }^{1}$ William R. Jacobs, Jr, ${ }^{2}$

\begin{abstract}
Mycobacteriophages have played an important role in the development of genetic tools and diagnostics for pathogenic mycobacteria, including Mycobacterium tuberculosis. However, despite the isolation of numerous phages that infect mycobacteria, the mechanisms of mycobacteriophage infection remain poorly understood, and knowledge about phage receptors is minimal. In an effort to identify the receptor for phage I3, we screened a library of Mycobacterium smegmatis transposon mutants for phage-resistant strains. All four phage 13-resistant mutants isolated were found to have transposon insertions in genes located in a cluster involved in the biosynthesis of the cell-wall-associated glycopeptidolipid (GPL), and consequently the mutants did not synthesize GPLs. The loss of GPLs correlated specifically with phage I3 resistance, as all mutants retained sensitivity to two other mycobacteriophages: D29 and Bxz1. In order to define the minimal receptor for phage 13 , we then tested the phage sensitivity of previously described GPL-deficient mutants of $M$. smegmatis that accumulate biosynthesis intermediates of GPLs. The results indicated that, while the removal of most sugar residues from the fatty acyl tetrapeptide (FATP) core of GPL did not affect sensitivity to phage 13 , a single methylated rhamnose, transferred by the rhamnosyltransferase Gtf2 to the FATP core, was critical for phage binding.
\end{abstract}

\section{INTRODUCTION}

Phages that infect mycobacteria have played an important role in the development of genetic tools for mycobacteria, particularly Mycobacterium tuberculosis, which is the causative agent of tuberculosis (Bardarov et al., 1997, 2002; Jacobs et al., 1991; Lee et al., 2004; Raj \& Ramakrishnan, 1970; Snapper et al., 1988; van Kessel et al., 2008). Recombinant mycobacteriophages have also been used for phage typing of clinical isolates (Kubica, 1982; Rado et al., 1975), in diagnostics (Carriere et al., 1997; Hazbon et al., 2003; Jacobs et al., 1993; McNerney \& Traore, 2005; Piuri et al., 2009; Riska et al., 1999), and as therapeutic agents for mycobacterial diseases (Broxmeyer et al., 2002; Mankiewicz \& Beland, 1964). For the further development of mycobacteriophages as genetic tools for manipulation of mycobacteria, and as diagnostic and therapeutic agents, it is necessary to understand the mechanism of interactions between mycobacteriophages and mycobacteria. Attachment of a phage by binding to its receptor on the mycobacterial cell surface is important for initiating infection, and the study of phage-resistant

Abbreviations: FATP, fatty acyl tetrapeptide; GPL, glycopeptidolipid. mutants defective in phage adsorption is a useful approach to identifying these receptors. While a number of cell wall components have been implicated in roles as phage receptors (Besra et al., 1994; Bisso et al., 1976; Dhariwal et al., 1986; Furuchi \& Tokunaga, 1972), no defined mycobacteriophage-resistant mutant with a missing phage receptor has been characterized to date. The only report of a mycobacteriophage-resistant mutant describes the appearance of a new lipid species (rather than the disappearance of an existing component) in a Mycobacterium smegmatis transposon mutant that was resistant to phage D29 (Besra et al., 1994). A study by Barsom \& Hatfull (1996) demonstrated that overexpression of the M. smegmatis gene $m p r$ confers resistance to multiple mycobacteriophages, but the function of $m p r$ remains unknown.

Phage receptors would be expected to be outer components of the bacterial cell wall, and thus phage-resistant mutants would also be an extremely useful resource for identification of biosynthetic pathways of mycobacterial cell wall components. Indeed, studies of interactions of bacteriophages with host cells have often led to discovery of bacterial cell surface receptors and transporters that play important roles in microbial physiology (Heller, 1992; Estrela et al., 1991; Tran et al., 1999). 
Phage I3 is a generalized transducing phage belonging to the Myoviridae family. It infects M. smegmatis, and it has found utility as a genetic tool for generalized transduction (Raj \& Ramakrishnan, 1970). In this study, we used phageI3-resistant mutants of $M$. smegmatis isolated from a transposon library to define the receptor for phage I3, and to demonstrate the utility of phage-resistant mutants for identification of genes involved in the biosynthesis of mycobacterial cell wall components.

\section{METHODS}

Bacterial strains, plasmids, phages and culture conditions. Bacterial strains, phages and plasmids used in this study are listed in Table 1. M. smegmatis strains were grown at $37{ }^{\circ} \mathrm{C}$ in Middlebrook 7H9 broth or tryptic soy broth (TSB), or on Middlebrook 7H10 medium or TSB agar (Becton Dickinson). For selection of $M$. smegmatis, kanamycin and hygromycin were used at concentrations of $25 \mu \mathrm{g} \mathrm{ml}^{-1}$ and $100 \mu \mathrm{g} \mathrm{ml}^{-1}$, respectively. Escherichia coli strains were routinely grown in Luria-Bertani broth at $37^{\circ} \mathrm{C}$, with $100 \mu \mathrm{g}$ ampicillin $\mathrm{ml}^{-1}$ or $150 \mu \mathrm{g}$ hygromycin $\mathrm{ml}^{-1}$ used for selection. High titres of phages were prepared, and phage titres were determined, according to protocols described by Larsen et al. (2007). Sensitivity of M. smegmatis strains to different phages was determined by spotting $10 \mu \mathrm{l}$ of a serial 10 -fold dilution $\left(10^{-3}-10^{-7}\right)$ of phage onto a $7 \mathrm{H} 9$ agar plate that contained an overlay of soft agar $(7 \mathrm{H} 9+0.6 \%$ agar) mixed with $100 \mu \mathrm{l}$ mid-exponential culture of $M$. smegmatis $\mathrm{mc}^{2} 155$. Plates were incubated at $37{ }^{\circ} \mathrm{C}$ for 2 days to visualize plaques.

Isolation of phage-I3-resistant mutants. Temperature-sensitive transposon-delivery phages phAE185 (containing Tn5370; McAdam et al., 2002) and phAE181 (containing Tn5371; Kriakov et al., 2003) were used to construct transposon mutant libraries of M. smegmatis $\mathrm{mc}^{2} 155$, according to protocols described by Larsen et al. (2007). For isolation of phage-I3-resistant mutants, individual transposon mutants were pre-inoculated in 96-well plates, and then replicated with a 96-spike replicator onto rectangular plates containing TSB agar pre-seeded with a suspension of I3 phage $\left(10^{10}\right.$ p.f.u. per plate), to screen for strains resistant to killing by phage. Single colonies of each candidate strain were then cultured and re-tested for phage resistance.
Detection of intracellular phage I3 DNA. M. smegmatis strains, grown to an $\mathrm{OD}_{600}$ of 1.0 , were washed with MP buffer [50 mM Tris/ $\mathrm{HCl}$ (pH 7.8), $150 \mathrm{mM} \mathrm{NaCl}, 10 \mathrm{mM} \mathrm{MgSO}_{4}, 2 \mathrm{mM} \mathrm{CaCl}_{2}$ ], and incubated with phage I3 (m.o.i. 1) for $1 \mathrm{~h}$ at $37{ }^{\circ} \mathrm{C}$. The suspension was then centrifuged at 3000 r.p.m. (MSE 43124-141 rotor) and the cell pellet was washed once in PBS, resuspended in $1 \mathrm{ml}$ DNase I reaction buffer $[20 \mathrm{mM}$ Tris/ $\mathrm{HCl}(\mathrm{pH} 8.4), 2 \mathrm{mM} \mathrm{MgCl}, 50 \mathrm{mM}$ $\mathrm{KCl}$ containing 3 units DNase I, and incubated for $20 \mathrm{~min}$ at $37^{\circ} \mathrm{C}$ for digestion of any traces of phage DNA. DNase I was then inactivated by adding EDTA solution to a final concentration of $2 \mathrm{mM}$, and heating for $10 \mathrm{~min}$ at $65{ }^{\circ} \mathrm{C}$. The cell pellet was washed four times with PBS containing $0.1 \%$ Tween-80. Total DNA was then extracted from the washed cell pellet using standard protocols (Larsen et al., 2007), and it was used as template for PCR detection of intracellular phage I3 DNA. The primers I317kD-F (5'-GTACAACCCGCCAACCCAC-3') and I317kD-R (5'-CAGGCGGACGAGATAGGTG-3'), designed to amplify part (461 bp) of a phage I3 gene encoding a $17 \mathrm{kDa}$ structural protein (Ramesh \& Gopinathan, 1994), were used for PCR amplification.

Isolation and sequencing of transposon-insertion sites. For all phage-I3-resistant mutants, with the exception of I3R-1, BssHIIdigested genomic DNA was used in a ligation reaction. To select for self-ligated fragments of genomic DNA containing Tn5371 (containing hyg and the R6K ori), the ligation mix was transformed into E. coli CC118ipir (Herrero et al., 1990). Plasmid DNA isolated from hygromycin-resistant transformants was then sequenced using the primers Tn5371-L (5'-AGTGCCACCTAAATTGTAAGC- $\left.3^{\prime}\right)$ and Tn5371-R (5'-TAGACAGATCGCTGAGATAGG-3') to obtain sequences of the left and right regions, respectively, flanking the transposon insertion. For the mutant I3R-1, genomic DNA was digested with BamHI, and then ligated into BamHI-digested pUC19 (Yanisch-Perron et al., 1985). Recombinant clones containing the transposon-insertion-containing genomic DNA fragment were isolated by selecting E. coli Top10 (Invitrogen) transformed with the ligation mix on Luria-Bertani agar containing ampicillin and hygromycin. Transposon-insertion sites were identified by sequencing plasmid DNA isolated from hygromycin- and ampicillin-resistant transformants using the primer HOPS1 (5'-GGCGTAGGAACCTCCATCATC-3') or HOPS2 (5'-CTTGCTCTTCCGCTTCTTCTCC-3').

Biochemical characterization of $\boldsymbol{M}$. smegmatis strains. Polar and apolar lipids (labelled with $\left[{ }^{14} \mathrm{C}\right]$ acetate) were extracted by using the methods described by Dobson et al. (1985). Glycopeptidolipids

Table 1. Mycobacterial strains and phages

\begin{tabular}{|c|c|c|}
\hline Strain or phage & Description & Reference \\
\hline$\Delta g t f 2$ & gtf 2 disruptant of $\mathrm{mc}^{2} 155$ & Miyamoto et al. (2006) \\
\hline$\Delta g t f 3$ & gtf3 disruptant of $\mathrm{mc}^{2} 155$ & Miyamoto et al. (2006) \\
\hline$\Delta g t f 2-\mathrm{pMV} 261 g t f 2$ & $\Delta g t f 2$ complemented with a $g t f 2$-containing plasmid & Miyamoto et al. (2006) \\
\hline $\mathrm{I} 3$ & Generalized transducing mycobacteriophage & Raj \& Ramakrishnan (1970) \\
\hline D29 & Lytic mycobacteriophage & Froman et al. (1954) \\
\hline Bxz1 & Generalized transducing mycobacteriophage & Lee et al. (2004) \\
\hline phAE185 & $\begin{array}{l}\text { Temperature-sensitive derivative of mycobacteriophage TM4 containing } \\
\text { the IS1096-derived transposon Tn } 5370\end{array}$ & McAdam et al. (2002) \\
\hline phAE181 & $\begin{array}{l}\text { Temperature-sensitive derivative of mycobacteriophage TM4 containing } \\
\text { the Himarl-derived transposon } \operatorname{Tn} 5371\end{array}$ & Kriakov et al. (2003) \\
\hline
\end{tabular}


(GPLs) from polar lipids were separated by TLC, following base treatment, as described previously (Burguiere et al., 2005). $\left[{ }^{14} \mathrm{C}\right]-$ labelled lipids on TLC plates were visualized after overnight exposure to Kodak X-Omat film.

\section{RESULTS}

\section{Isolation of phage-13-resistant mutants of M. smegmatis from a random transposon library}

Libraries of $M$. smegmatis random transposon mutants, generated using either the IS1096-derived transposon Tn5370 (Cirillo et al., 1991; McAdam et al., 2002), or the Himar1-derived transposon Tn5371 (Kriakov et al., 2003), were screened for resistance to lysis by phage I3 by replicating 96-well plates containing transposon mutants on agar plates pre-seeded with phage I3. After single colony purification, the putative phage-resistant mutants were subjected to a second culture passage in the presence of phage to yield four bonafide phage-I3-resistant mutants (no plaques were observed when a suspension of phage I3 was spotted onto lawns of individual mutant strains; Fig. 1). Intracellular phage I3 genomic DNA was detected by PCR from M. smegmatis $\mathrm{mc}^{2} 155$ cells pre-adsorbed with phage I3, but not from phage-resistant mutants, indicating that the phage failed to inject DNA into the phage-resistant mutants (Fig. 2).

\section{Phage-I3-resistant $M$. smegmatis mutant strains are defective in GPL biosynthesis}

Following the cloning of transposon-tagged genomic insertion sites from the phage-I3-resistant mutants in $E$. coli, the transposon-disrupted genes were identified by sequencing using transposon-specific primers (Table 2). All of four I3-resistant mutants were found to contain insertions that mapped to a cluster of genes involved in the biosynthesis of GPLs (Table 2). GPLs are a group of complex lipids derived from an acylated non-ribosomal tetrapeptide core and carbohydrate moieties, and they are abundant in the outer envelope of M. smegmatis and other mycobacteria (Billman-Jacobe, 2004; Schorey \& Sweet, 2008). M. smegmatis produces six subclasses of GPLs, each of which has a common fatty acyl tetrapeptide (FATP) core consisting of a tetrapeptide amino alcohol (D-Phe-D-alloThr-D-Ala-L-alaninol) linked to a $\mathrm{C}_{26}-\mathrm{C}_{34}$ fatty acyl chain via an amide bond (Miyamoto et al., 2006; Fig. 3a). GPL-1, $-2,-3$ and -4 contain a rhamnose (with varying levels of $O-$ methylation) and di-acetylated 6-deoxytalose as sugar residues. GPL-5 and -6 contain an additional O-methyl rhamnose attached to the original rhamnose residue (Miyamoto et al., 2006).

Given the association of the transposon insertions with genes involved in GPL biosynthesis, we conducted a thorough analysis of polar and apolar lipids from the phage-resistant mutant strains using 2D TLC (Dobson et al., 1985). The analysis revealed a loss of GPLs in all mutants (Fig. $4 \mathrm{~b}-\mathrm{e}$ ). None of the other cell-wall-associated lipids was altered in any of the mutants (data not shown). Additionally, TLC analysis used for separation of deacetylated subclasses 1-4 of GPLs showed that these subclasses were absent in the mutant strains (Fig. 4f). These results suggested a role for GPLs in binding of phage I3 to the M. smegmatis cell surface.

\section{Loss of GPLs does not result in resistance to other mycobacteriophages}

Given the location of GPLs as one of the outer glycolipids of the M. smegmatis cell envelope, it was possible that

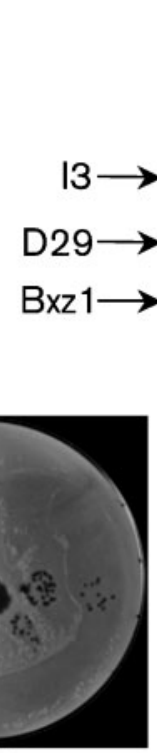

I3R-2
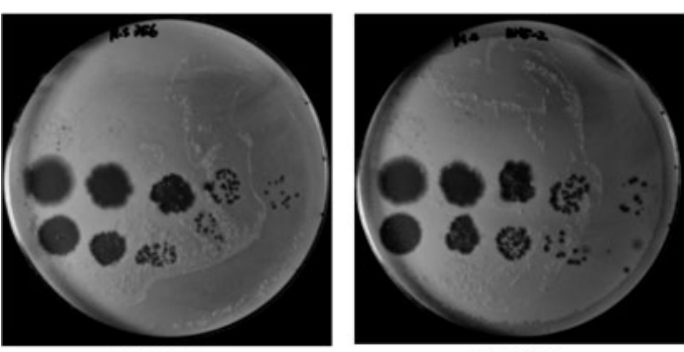

I3R-3

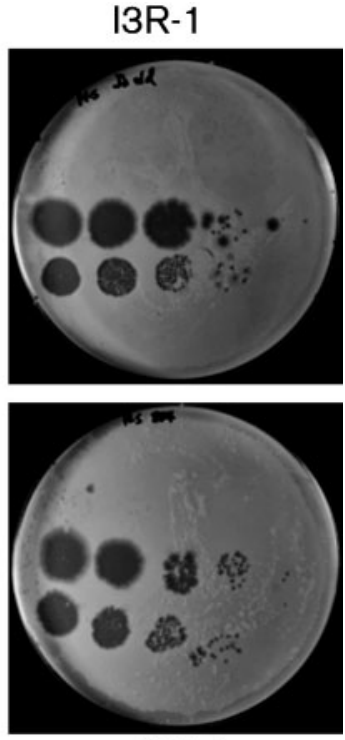

I3R-4
Fig. 1. Phage sensitivity of phage-13-resistant mutants. Tenfold dilutions $\left(10^{-3}-10^{-7}\right)$ of phages 13, D29 and Bxz1 were spotted from left to right on soft agar overlays on $7 \mathrm{H} 9$ agar plates containing either parental $\left(\mathrm{mc}^{2} 155\right)$ or phage-I3-resistant strains. 


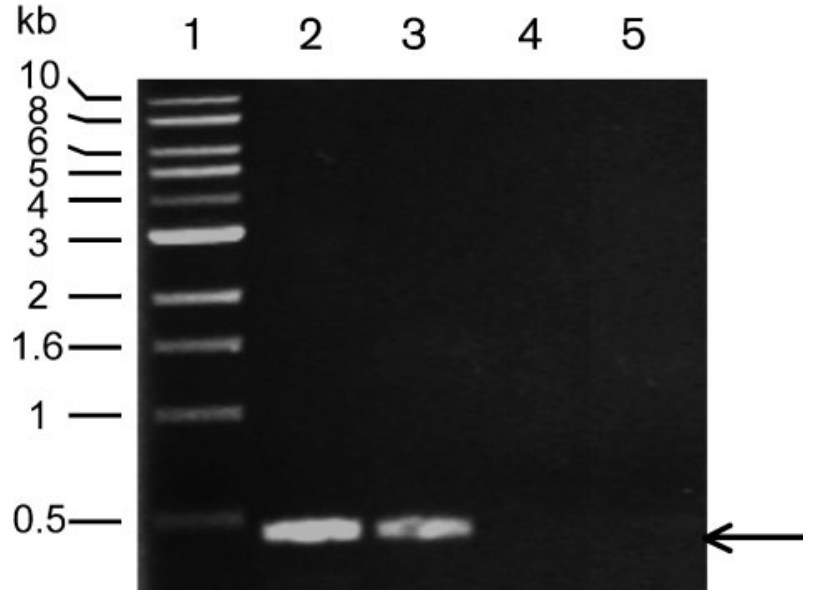

Fig. 2. $P C R$ amplification of part (461 bp) of a phage 13 gene encoding a $17 \mathrm{kDa}$ structural protein. Lanes: 1, DNA size markers; 2, PCR positive control using phage I3 DNA as a template; 3, 4 and $5, P C R$ using total DNA extracted from $M$. smegmatis strains $\mathrm{mc}^{2} 155, \mathrm{I3R}-1$ and $\Delta g t f 2$, respectively, each of which was preadsorbed with phage 13 . The expected band size is indicated by an arrow.

phage resistance was not due to loss of a phage I3 receptor, but due to a non-specific effect affecting adsorption of all mycobacteriophages. However, when we tested the sensitivity of the phage-I3-resistant mutants to two other lytic mycobacteriophages (D29 and Bxz1), both phages were able to form plaques on lawns of the phage-I3-resistant mutants, indicating that GPL deficiency caused resistance that was specific to phage I3 (Fig. 1). Thus, GPLs are likely to be the receptors for phage I3.

\section{Minimal structural requirements for the phage 13 receptor}

The sequence of assembly of sugar residues in GPLs was identified by Miyamoto et al. (2006) by specifically deleting $g t f 1, g t f 2$ or $g t f 3$, which are three genes encoding glycosyltransferases in $M$. smegmatis $\mathrm{mc}^{2} 155$. Gtfl is involved in the transfer of deoxytalose to the FATP core, and consequently the $\Delta g t f 1$ mutant lacked all classes of GPLs, and instead accumulated the intermediates FATP3,4-di-O-methyl rhamnose and FATP-2,3,4-tri-O-methyl rhamnose (FATP-di-O-Me-Rha and FATP-tri-O-methyl- rhamnose; Fig. 3b, c). Similarly, Gtf2 is involved, independently, in the transfer of rhamnose to the FATP core, and the $\Delta$ gtf2 mutant, which also lacked all classes of GPLs, accumulated FATP-6-deoxytalose. (Fig. 3d). On the other hand, Gtf3 is involved in the transfer of the second rhamnose residue, and subsequently only GPL-5 and -6 were missing in the $\Delta g t f 3$ mutant. The accumulation of different intermediates of GPL biosynthesis in these mutants allowed us to utilize these strains to identify the specific structural components of GPL that defined the receptor of phage I3. The $\Delta g t f 1$ and $\Delta g t f 3$ mutants were sensitive to infection by phage $\mathrm{I} 3$, though the plaquing efficiency of phage I 3 on a lawn of the $\Delta g t f 1$ mutant was diminished (Fig. 5). On the other hand, the $\Delta g t f 2$ mutant was found to be phage resistant, and complementation of the $\Delta g t f 2$ mutant with plasmid-encoded $g t f 2$ restored phage sensitivity (Fig. 5). This was consistent with the phageresistance phenotype of the transposon mutant I3R-1, which had a transposon insertion in gtf2 (Table 2). Also, resistance of the $\Delta g t f 2$ mutant to phage I3 correlated with the inability to detect intracellular phage DNA by PCR following adsorption with phage (Fig. 2). Similar to the I3resistant transposon mutants, the $\Delta g t f 2$ mutant retained sensitivity to phages D29 and Bxz1 (Fig. 5). Thus, collectively, these results indicate that while the 6deoxytalose residue is not essential for phage binding, addition of the first rhamnose residue to the FATP core is critical for phage I3 infection, and a mixture of FATP cores containing a di- or tri-O-methylated rhamnose is sufficient to allow binding of phage I3.

\section{DISCUSSION}

Most mycobacteriophages belong to the family Myoviridae or Siphoviridae; these families encompass phages with either contractile or long tails (Ackermann, 2001). It has been speculated that this tail morphology may be particularly relevant to mycobacteriophages, helping injection of phage DNA through an exceptionally thick, carbohydrate- and lipid-rich cell wall (Brennan \& Nikaido, 1995). Interestingly, the sequencing of a number of mycobacteriophage genomes has revealed that phagetail-associated tape measure proteins from mycobacteriophages contain a number of domains, some of which are similar to those involved in host-encoded peptidoglycandegrading enzymes (Piuri \& Hatfull, 2006), suggesting that these additional domains possibly aid viral DNA

Table 2. Transposon-disrupted genes in phage-I3-resistant mutants of $M$. smegmatis $\mathrm{mc}^{2} 155$

\begin{tabular}{|lll|}
\hline Mutant & Disrupted gene & \multicolumn{1}{c|}{ Function } \\
\hline I3R-1 & MSMEG0392 & Glycosyltransferase $(g t f 2)$ \\
I3R-2 & $M S M E G 0399$ & MbtH-like protein \\
I3R-3 & $M S M E G 0400$ & Non-ribosomal peptide synthase (mps1) \\
I3R-4 & $M S M E G 0401$ & Non-ribosomal peptide synthase $(m p s 2)$ \\
\end{tabular}


(a)

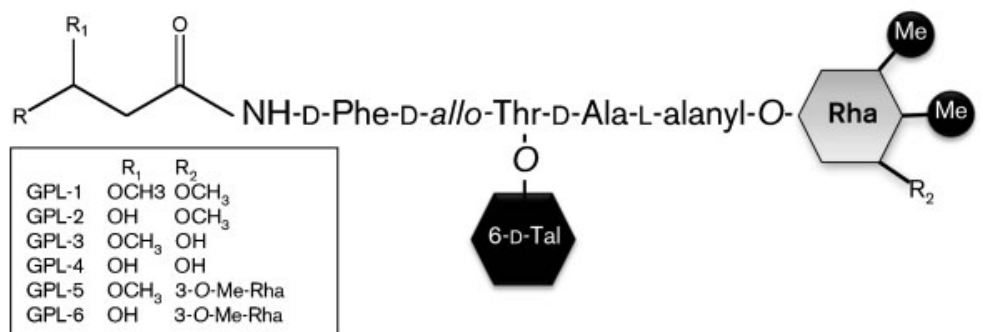

(b)

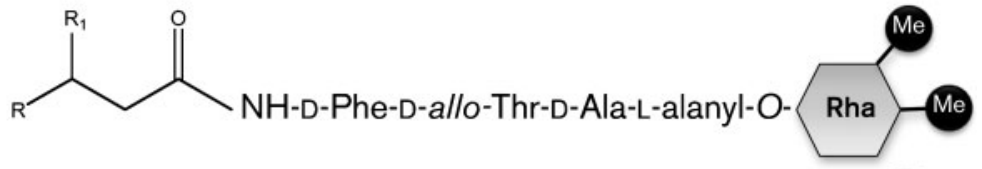

(c)

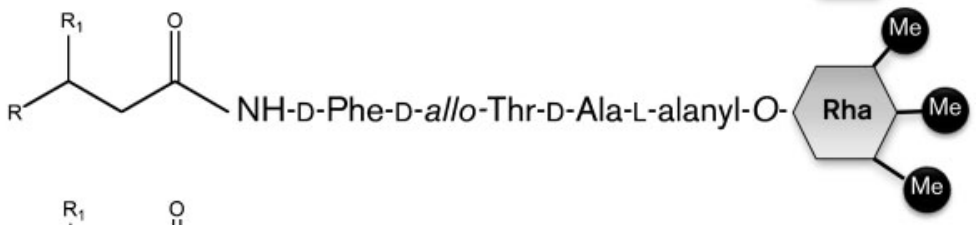

(d)

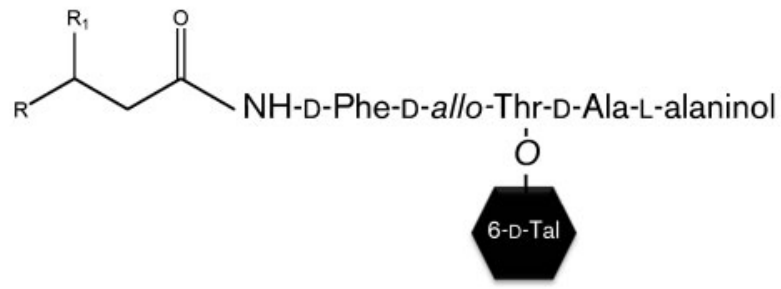

Fig. 3. Simplified representations of the structures of GPLs found in $M$. smegmatis $\mathrm{mc}^{2} 155$ (a), and biosynthetic intermediates that accumulate in $\Delta g t f 1(\mathrm{~b}, \mathrm{c})$ and $\Delta g t f 2(\mathrm{~d})$ mutants. Rha, rhamnose; 6-D-Tal, 6-deoxytalose; Me, methyl. Variations in the fatty acyl chain (R) and acetyl modifications of talose are not shown. injection via localized cell wall degradation, and thus play an important role in initiating infection. However, these early events in phage infection are dependent on, and preceded by, the specific binding of phage to its cell surface receptor on the bacterial envelope. In this study, we used transposon mutants and defined glycosyltransferase mutants to identify GPLs as the M. smegmatis cell surface receptors for phage I3, which belongs to the family Myoviridae.
Interestingly, Mycobacterium avium, which also produces GPLs, seems naturally resistant to phage I3 (Lee et al., 2004). This may be either because a rough variant of $M$. avium (that does not produce GPLs) was used to assay infectivity, or because the glycosylation of the deoxytalose residue in $M$. avium GPLs may have a 'masking' effect that prevents the recognition of methylated rhamnose by phage I3. M. tuberculosis, on the other hand, is naturally resistant to phage I3 because it does not synthesize GPLs.
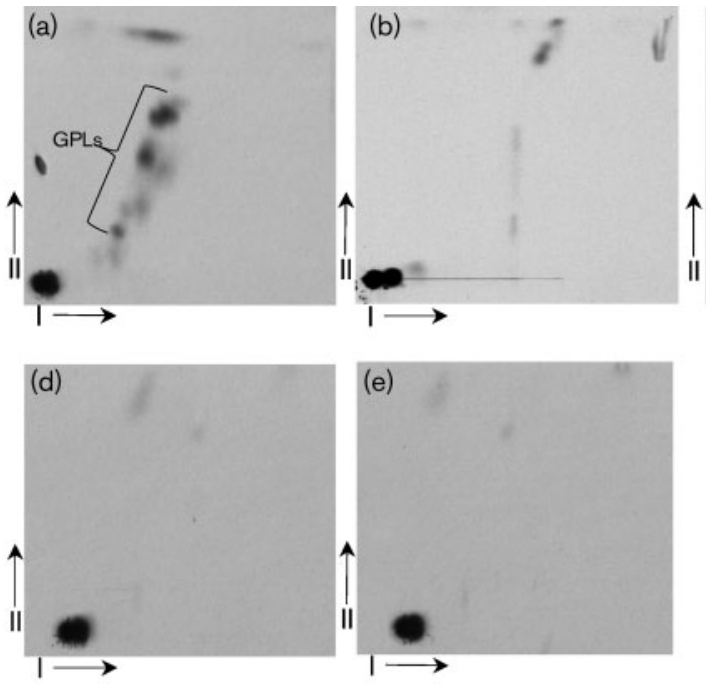

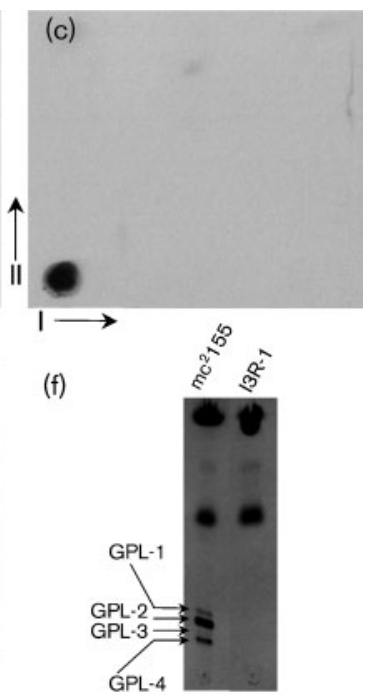

Fig. 4. TLC analysis of polar lipids extracted from parental $\left(\mathrm{mc}^{2} 155\right)$ and phage-l3-resistant mutants. (a-e) Autoradiographs of $\left[{ }^{14} \mathrm{C}\right]-$ labelled polar lipids resolved using chloroform/ methanol/water $(100: 14: 0.8)$ for direction I, and chloroform/acetone/methanol/water (50:60:2.5:3) for direction II. (a) $\mathrm{mc}^{2} 155$, (b) I3R-1, (c) I3R-2, (d) I3R-3, (e) I3R-4. (f) Deacetylated polar lipids were also run using the solvent system chloroform/methanol/water (90:10:1) to visualize GPLs $1,2,3$ and 4 . 


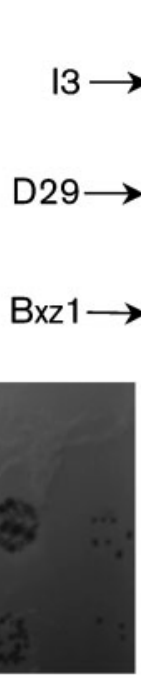

$\Delta g t f 2$
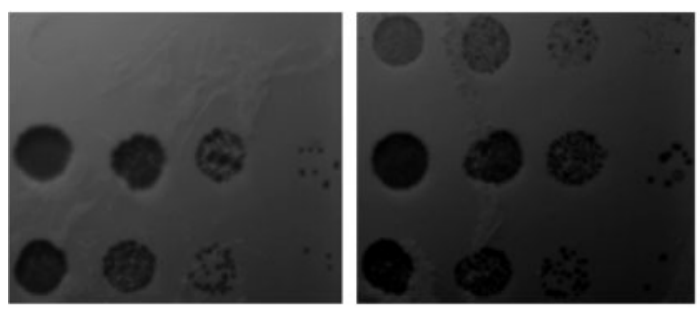

$\Delta g t f 2-p M V 261 g t f 2$
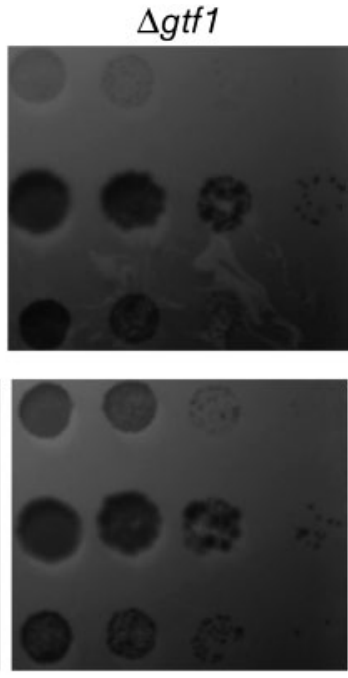

$\Delta g t f 3$
Fig. 5. Sensitivity of $M$. smegmatis GPLassociated glycosyltransferase mutants to phages 13, D29 and Bxz1. Tenfold dilutions of phages spotted from left to right on soft agar overlays on 7H9 agar plates containing either the parental strain $\left(\mathrm{mc}^{2} 155\right)$ or a glycosyltransferase mutant.
Apart for the identification of the phage $\mathrm{I} 3$ receptor, this work also highlighted the utility of phage-resistance screens to identify genes involved in the biosynthesis/transport of cell envelope components, as we isolated mutants defective in three different classes of genes (one glycosyltransferase, two non-ribosomal peptide synthases and one $m b t H$-like gene of unknown activity), all of which are involved in GPL biosynthesis. While in this case most of the genes involved in GPL biosynthesis have been studied in detail in the past, the availability of numerous mycobacteriophages would allow screening for mutants defective in other cell wall components that constitute the corresponding phage receptors. Indeed, this work showed that the phages D29 and Bxz1 have receptor(s) distinct from that for phage I3, as the I3-resistant mutants retained sensitivity to these phages. More than 250 mycobacteriophages have been isolated to date (Barksdale \& Kim, 1977; Hatfull \& Jacobs, 1994), and only a few have been studied in detail (Hatfull, 2005). Mycobacteriophages show diversity in genome sequences, morphology and host range (Pedulla et al., 2003; Sampson et al., 2009), and it is quite likely that this diversity is also reflected in the nature of their corresponding receptors in the cell walls of mycobacteria. In addition, studies on phage receptors may aid the further development of phage typing as a diagnostic tool for the identification of strains of pathogenic mycobacteria that produce variants of cell surface components.

\section{ACKNOWLEDGEMENTS}

The authors would like to thank Yuji Miyamoto, Tetsu Mukai and Masahiko Makino (National Institute of Infectious Diseases, Tokyo, Japan) for the generous gift of the M. smegmatis glycosyltransferase mutants. J.C. is the recipient of a $\mathrm{PhD}$ studentship from the Darwin Trust of Edinburgh. G.S. B. acknowledges support from the Medical Research Council, the Royal Society and Mr James Bardrick. A. B. is supported by a Career Development Award from the Medical Research Council.

\section{REFERENCES}

Ackermann, H. W. (2001). Frequency of morphological phage descriptions in the year 2000. Brief review. Arch Virol 146, 843-857.

Bardarov, S., Kriakov, J., Carriere, C., Yu, S., Vaamonde, C., McAdam, R. A., Bloom, B. R., Hatfull, G. F. \& Jacobs, W. R., Jr (1997). Conditionally replicating mycobacteriophages: a system for transposon delivery to Mycobacterium tuberculosis. Proc Natl Acad Sci U S A 94, 10961-10966.

Bardarov, S., Bardarov, S., Jr, Pavelka, M. S., Jr, Sambandamurthy, V., Larsen, M., Tufariello, J., Chan, J., Hatfull, G. \& Jacobs, W. R., Jr (2002). Specialized transduction: an efficient method for generating marked and unmarked targeted gene disruptions in Mycobacterium tuberculosis, M. bovis BCG and M. smegmatis. Microbiology 148, 3007-3017.

Barksdale, L. \& Kim, K. S. (1977). Mycobacterium. Bacteriol Rev 41, 217-372.

Barsom, E. K. \& Hatfull, G. F. (1996). Characterization of Mycobacterium smegmatis gene that confers resistance to phages L5 and D29 when overexpressed. Mol Microbiol 21, 159-170.

Besra, G. S., Khoo, K. H., Belisle, J. T., McNeil, M. R., Morris, H. R., Dell, A. \& Brennan, P. J. (1994). New pyruvylated, glycosylated acyltrehaloses from Mycobacterium smegmatis strains, and their implications for phage resistance in mycobacteria. Carbohydr Res 251, 99-114.

Billman-Jacobe, H. (2004). Glycopeptidolipid synthesis in mycobacteria. Curr Sci 86, 111-114.

Bisso, G., Castelnuovo, G., Nardelli, M. G., Orefici, G., Arancia, G., Laneelle, G., Asselineau, C. \& Asselineau, J. (1976). A study on the receptor for a mycobacteriophage: phage phlei. Biochimie 58, 87-97.

Brennan, P. J. \& Nikaido, H. (1995). The envelope of mycobacteria. Annu Rev Biochem 64, 29-63.

Broxmeyer, L., Sosnowska, D., Miltner, E., Chacon, O., Wagner, D., McGarvey, J., Barletta, R. G. \& Bermudez, L. E. (2002). Killing of Mycobacterium avium and Mycobacterium tuberculosis by a mycobacteriophage delivered by a nonvirulent mycobacterium: a model for phage therapy of intracellular bacterial pathogens. J Infect Dis 186, 1155-1160.

Burguiere, A., Hitchen, P. G., Dover, L. G., Dell, A. \& Besra, G. S. (2005). Altered expression profile of mycobacterial surface glycopep- 
tidolipids following treatment with the antifungal azole inhibitors econazole and clotrimazole. Microbiology 151, 2087-2095.

Carriere, C., Riska, P. F., Zimhony, O., Kriakov, J., Bardarov, S., Burns, J., Chan, J. \& Jacobs, W. R., Jr (1997). Conditionally replicating luciferase reporter phages: improved sensitivity for rapid detection and assessment of drug susceptibility of Mycobacterium tuberculosis. J Clin Microbiol 35, 3232-3239.

Cirillo, J. D., Barletta, R. G., Bloom, B. R. \& Jacobs, W. R., Jr (1991). A novel transposon trap for mycobacteria: isolation and characterization of IS1096. J Bacteriol 173, 7772-7780.

Dhariwal, K. R., Liav, A., Vatter, A. E., Dhariwal, G. \& Goren, M. B. (1986). Haptenic oligosaccharides in antigenic variants of mycobacterial C-mycosides antagonize lipid receptor activity for mycobacteriophage D4 by masking a methylated rhamnose. J Bacteriol 168, 283293.

Dobson, G., Minnikin, D. E., Minnikin, S. M., Parlett, J. H., Goodfellow, M., Ridell, M. \& Magnusson, M. (1985). Systematic analysis of complex mycobacterial lipids. In Chemical Methods in Bacterial Systematics, pp. 237-265. Edited by M. Goodfellow \& D. E. Minnikin. London: Academic Press.

Estrela, A. I., Pooley, H. M., de Lencastre, H. \& Karamata, D. (1991). Genetic and biochemical characterization of Bacillus subtilis 168 mutants specifically blocked in the synthesis of the teichoic acid poly(3-O- $\beta$-D-glucopyranosyl- $N$-acetylgalactosamine 1-phosphate): gneA, a new locus, is associated with UDP- $N$-acetylglucosamine 4epimerase activity. J Gen Microbiol 137, 943-950.

Froman, S., Will, D. W. \& Bogen, E. (1954). Bacteriophage active against virulent Mycobacterium tuberculosis. I. Isolation and activity. Am J Public Health Nations Health 44, 1326-1333.

Furuchi, A. \& Tokunaga, T. (1972). Nature of the receptor substance of Mycobacterium smegmatis for D4 bacteriophage adsorption. $J$ Bacteriol 111, 404-411.

Hatfull, G. H. (2005). Mycobacteriophages and tuberculosis. In Tuberculosis and the Tubercle Bacillus, pp. 203-218. Edited by S. T. Cole, D. Eisenach, D. N. McMurray \& W. R. Jacobs Jr. Washington, DC: American Society for Microbiology.

Hatfull, G. F. \& Jacobs, W. R., Jr (1994). Mycobacteriophages: cornerstones of mycobacterial research. In Tuberculosis: Pathogenesis, Protection and Control, pp. 165-183. Edited by B. R. Bloom. Washington, DC: American Society for Microbiology.

Hazbon, M. H., Guarin, N., Ferro, B. E., Rodriguez, A. L., Labrada, L. A., Tovar, R., Riska, P. F. \& Jacobs, W. R., Jr (2003). Photographic and luminometric detection of luciferase reporter phages for drug susceptibility testing of clinical Mycobacterium tuberculosis isolates. J Clin Microbiol 41, 4865-4869.

Heller, K. J. (1992). Molecular interaction between bacteriophage and the gram-negative cell envelope. Arch Microbiol 158, 235-248.

Herrero, M., de Lorenzo, V. \& Timmis, K. N. (1990). Transposon vectors containing non-antibiotic resistance selection markers for cloning and stable chromosomal insertion of foreign genes in gramnegative bacteria. J Bacteriol 172, 6557-6567.

Jacobs, W. R., Jr, Kalpana, G. V., Cirillo, J. D., Pascopella, L., Snapper, S. B., Udani, R. A., Jones, W., Barletta, R. G. \& Bloom, B. R. (1991). Genetic systems for mycobacteria. Methods Enzymol 204, 537-555.

Jacobs, W. R., Jr, Barletta, R. G., Udani, R., Chan, J., Kalkut, G., Sosne, G., Kieser, T., Sarkis, G. J., Hatfull, G. F. \& Bloom, B. R. (1993). Rapid assessment of drug susceptibilities of Mycobacterium tuberculosis by means of luciferase reporter phages. Science 260, 819-822.

Kriakov, J., Lee, S. \& Jacobs, W. R., Jr (2003). Identification of a regulated alkaline phosphatase, a cell surface-associated lipoprotein, in Mycobacterium smegmatis. J Bacteriol 185, 4983-4991.
Kubica, G. P. (1982). Phage typing of Mycobacterium tuberculosis: a time for standardization. Am Rev Respir Dis 126, 3-4.

Larsen, M. H., Biermann, K., Tandberg, S., Hsu, T. \& Jacobs, W. R., Jr (2007). Genetic manipulation of Mycobacterium tuberculosis. Curr Protoc Microbiol Chapter 10, Unit 10A.2.

Lee, S., Kriakov, J., Vilcheze, C., Dai, Z., Hatfull, G. F. \& Jacobs, W. R., Jr (2004). Bxz1, a new generalized transducing phage for mycobacteria. FEMS Microbiol Lett 241, 271-276.

Mankiewicz, E. \& Beland, J. (1964). The role of mycobacteriophages and of cortisone in experimental tuberculosis and sarcoidosis. Am Rev Respir Dis 89, 707-720.

McAdam, R. A., Quan, S., Smith, D. A., Bardarov, S., Betts, J. C., Cook, F. C., Hooker, E. U., Lewis, A. P., Woollard, P. \& other authors (2002). Characterization of a Mycobacterium tuberculosis H37Rv transposon library reveals insertions in 351 ORFs and mutants with altered virulence. Microbiology 148, 2975-2986.

McNerney, R. \& Traore, H. (2005). Mycobacteriophage and their application to disease control. J Appl Microbiol 99, 223-233.

Miyamoto, Y., Mukai, T., Nakata, N., Maeda, Y., Kai, M., Naka, T., Yano, I. \& Makino, M. (2006). Identification and characterization of the genes involved in glycosylation pathways of mycobacterial glycopeptidolipid biosynthesis. J Bacteriol 188, 86-95.

Pedulla, M. L., Ford, M. E., Houtz, J. M., Karthikeyan, T., Wadsworth, C., Lewis, J. A., Jacobs-Sera, D., Falbo, J., Gross, J. \& other authors (2003). Origins of highly mosaic mycobacteriophage genomes. Cell 113, 171-182.

Piuri, M. \& Hatfull, G. F. (2006). A peptidoglycan hydrolase motif within the mycobacteriophage TM4 tape measure protein promotes efficient infection of stationary phase cells. Mol Microbiol 62, 15691585.

Piuri, M., Jacobs, W. R., Jr \& Hatfull, G. F. (2009). Fluoromycobacteriophages for rapid, specific, and sensitive antibiotic susceptibility testing of Mycobacterium tuberculosis. PLoS One 4, e4870.

Rado, T. A., Bates, J. H., Engel, H. W., Mankiewicz, E., Murohashi, T., Mizuguchi, Y. \& Sula, L. (1975). World Health Organization studies on bacteriophage typing of mycobacteria. Subdivision of the species Mycobacterium tuberculosis. Am Rev Respir Dis 111, 459-468.

Raj, C. V. \& Ramakrishnan, T. (1970). Transduction in Mycobacterium smegmatis. Nature 228, 280-281.

Ramesh, G. R. \& Gopinathan, K. P. (1994). Structural proteins of mycobacteriophage I3: cloning, expression and sequence analysis of a gene encoding a $70 \mathrm{kDa}$ structural protein. Gene 143, 95-100.

Riska, P. F., Su, Y., Bardarov, S., Freundlich, L., Sarkis, G., Hatfull, G., Carrière, C., Kumar, V., Chan, J. \& Jacobs, W. R., Jr (1999). Rapid film-based determination of antibiotic susceptibilities of Mycobacterium tuberculosis strains by using a luciferase reporter phage and the Bronx Box. J Clin Microbiol 37, 1144-1149.

Sampson, T., Broussard, G. W., Marinelli, L. J., Jacobs-Sera, D., Ray, M., Ko, C. C., Russell, D., Hendrix, R. W. \& Hatfull, G. F. (2009). Mycobacteriophages BPs, Angel, and Halo: comparative genomics reveals a novel class of ultra small mobile genetic elements. Microbiology 155, 2962-2977.

Schorey, J. S. \& Sweet, L. (2008). The mycobacterial glycopeptidolipids: structure, function, and their role in pathogenesis. Glycobiology 18, 832-841.

Snapper, S. B., Lugosi, L., Jekkel, A., Melton, R. E., Kieser, T., Bloom, B. R. \& Jacobs, W. R., Jr (1988). Lysogeny and transformation in mycobacteria: stable expression of foreign genes. Proc Natl Acad Sci U S A 85, 6987-6991.

Snapper, S. B., Melton, R. E., Mustafa, S., Kieser, T. \& Jacobs, W. R., Jr (1990). Isolation and characterization of efficient plasmid 
transformation mutants of Mycobacterium smegmatis. Mol Microbiol 4, 1911-1919.

Tran, H. L., Fiedler, F., Hodgson, D. A. \& Kathariou, S. (1999).

Transposon-induced mutations in two loci of Listeria monocytogenes serotype $1 / 2 \mathrm{a}$ result in phage resistance and lack of $N$-acetylglucosamine in the teichoic acid of the cell wall. Appl Environ Microbiol 65, 4793-4798. van Kessel, J. C., Marinelli, L. J. \& Hatfull, G. F. (2008). Recombineering mycobacteria and their phages. Nat Rev Microbiol 6, 851-857.

Yanisch-Perron, C., Vieira, J. \& Messing, J. (1985). Improved M13 phage cloning vectors and host strains: nucleotide sequences of the M13mp18 and pUC19 vectors. Gene 33, 103-119.

Edited by: S. V. Gordon 